\title{
EL DIFÍCIL ENCAJE ENTRE REFERÉNDUM Y DEMOCRACIA REPRESENTATIVA: REFLEXIONES DESDE ESPAÑA
}

José Luis López González Montserrat De Santiago

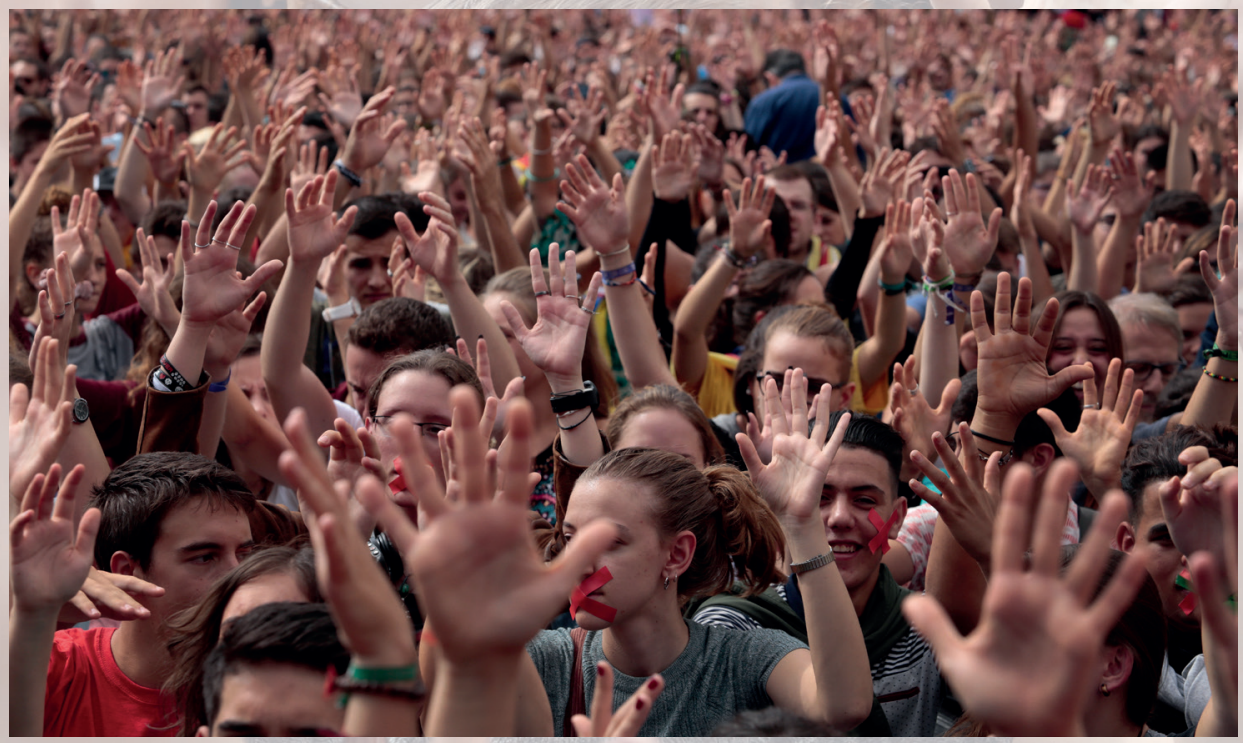





\title{
EL DIFÍCIL ENCAJE ENTRE REFERÉNDUM Y DEMOCRACIA REPRESENTATIVA: REFLEXIONES DESDE ESPAÑA
}

\author{
José LuIS LÓPEZ GONZÁLEZ \\ Montserrat De Santiago \\ Universidad Autónoma de Madrid
}

\section{Resumen}

La participación política es esencial para caracterizar el ordenamiento jurídico como democrático (CE, arts. 9.2 y 23). El referéndum se configura como una modalidad del sistema español de participación política, complementaria de la democracia representativa, que es versátil para la adopción de decisiones de especial trascendencia y para la ratificación o la reforma de los textos constitucionales, previamente aprobados en las asambleas constituyentes. ${ }^{1}$

Palabras clave: participación política, elecciones, derecho de sufragio, consulta popular, referéndum, referendo, plebiscito.

Los autores: José Luis López González, doctor en Derecho. Profesor titular de Derecho Constitucional de la Universidad Autónoma de Madrid, miembro de la Asociación de Constitucionalistas de España (ACE), codirector del Seminario de Derecho Deportivo de la Facultad de Derecho de la Universidad Autónoma de Madrid, socio fundador del Club Profesional Iustel. Correo electrónico: josel.lopez@uam.es

Montserrat de Santiago, doctora en Derecho, Ciencia Política y Criminología. Universidad de Valencia. Correo electrónico: mds49@madrid.org

Recibido: 26 de julio de 2019; evaluado: 14 de septiembre de 2019; aceptado: 18 de septiembre de 2019.

Este artículo es producto de una reflexión continuada sobre los problemas del referéndum como actividad electoral propia del sistema español de participación política, que arrancó en 2004 con diferentes publicaciones sobre este modo de participación democrática. 


\title{
THE DIFFICULT FIT BETWEEN THE REFERENDUM AND REPRESENTATIVE DEMOCRACY: REFLECTIONS FROM SPAIN
}

\author{
José LuIS LÓPEZ GoNZÁLEZ \\ Montserrat De Santiago \\ Autonomous University of Madrid
}

\begin{abstract}
Political participation is essential to the classification as democratic of the legal system (articles 9.2 and 23 of the Spanish Constitution). The referendum is designed as a method of political participation within the Spanish system, complementary to representative democracy, which is versatile for the adoption of particularly significant decisions and for the ratification or reform of constitutional texts, previously approved in constitutional assemblies.
\end{abstract}

Keywords: political participation, elections, voting rights, popular referendum, referendum, plebiscite

About the authors: José Luis López González, doctor in Law. Professor of Constitutional Law at the Autonomous University of Madrid, member of the Constitutionalist Association of Spain (ACE), co-director of the Seminar of Sporting Law in the Law Department of the Autonomous University of Madrid, founding member of the Iustel Professional Club, Email: josel.lopez@uam.es

Montserrat de Santiago, doctor in Law, Political Science, and Criminology. University of Valencia. Email: mds49@madrid.org

Received: July 26, 2019; evaluated: September 14, 2019; accepted: September 18, 2019. 


\title{
A DIFÍCIL LIGAÇÃO ENTRE REFERENDO E DEMOCRACIA REPRESENTATIVA: REFLEXÕES A PARTIR DA ESPANHA
}

\author{
JosÉ LuIS LÓPEZ GONZÁLEZ \\ Montserrat De Santiago \\ Universidad Autónoma de Madrid
}

\begin{abstract}
Resumo
A participação política é essencial para que um sistema legal seja classificado como democrático (artigos 9.2 e 23 da Constituição espanhola). O referendo é concebido como um método de participação política do sistema espanhol, complementar à democracia representativa, particularmente diverso para a implementação de decisões de especial importância de natureza praticamente irreversível e para a ratificação de textos constitucionais, ou sua modificação, previamente aprovada em assembleias constituintes.
\end{abstract}

Palavras-chave: participação política, eleições, direitos de voto, referendo popular, referendo, plebiscito.

Os autores: José Luis López González, doutor em Direito. Professor titular de Direito Constitucional da Universidad Autónoma de Madrid. Membro da Associação de Constitucionalistas da Espanha. Codiretor do Seminário de Direito Desportivo da Faculdade de Direito da Universidad Autónoma de Madrid, sócio-fundador do Clube Profissional Iustel. E-mail: josel.lopez@uam.es

Montserrat de Santiago, doutora em Direito, Ciência Política e Criminologia pela Universidad de Valencia. E-mail: mds49@madrid.org

Recebido: 26 de julho de 2019; avaliado: 14 de setembro de 2019; aceito: 18 de setembro de 2019. 


\section{Introducción}

La democracia debe guardarse de dos excesos: el espiritu de desigualdad, que la conduce a la aristocracia, y el espiritu de igualdad extrema, que la conduce al despotismo. ${ }^{2}$

El Artículo 92 de la Constitución española es el instrumento cardinal para una participación directa, es decir, una consulta popular en todo el ámbito nacional para todas las decisiones de especial trascendencia. En nuestro sistema constitucional, la democracia representativa — por ende, la democracia parlamentaria — es la norma ordinaria respaldada por el constituyente español, que ha optado, en primer lugar, por un sistema de democracia representativa prácticamente exclusiva y, en segundo lugar, por reconocer la institución del referéndum con carácter complementario.

Al reflexionar sobre la tesis constitucional que plantea el referéndum, se analizan también la discrepancia y la proximidad en algunos países iberoamericanos entre los términos referéndum y plebiscito; por consiguiente, no está de más adoptar estos conceptos como punto de partida. Para ello ha de consultarse el Diccionario de la Real Academia de la Lengua Española, que en su tenor literal señala:

referéndum

Del fr. référendum, y este del lat. referendum "lo que ha de ser consultado", n. del gerundivo de referre "consultar".

1. m. Procedimiento por el que se someten al voto popular leyes o decisiones políticas con carácter decisorio o consultivo. ${ }^{3}$

plebiscito

Del lat. plebiscìtum.

1. m. Resolución tomada por todo un pueblo por mayoría de votos.

2. m. Consulta que los poderes públicos someten al voto popular directo para que apruebe o rechace una determinada propuesta sobre una cuestión política o legal.

Charles Montesquieu, Del espiritu de las leyes (Madrid: Tecnos, 2007), 169.

3 Real Academia de la Lengua Española, "Referéndum" en Diccionario de la lengua española, http://dle.rae. es/?id=VcEQ6Jm (acceso mayo 18, 2018). 
3. m. En la antigua Roma, ley que la plebe establecía a propuesta de su tribuno, separadamente de las clases superiores de la república, y que obligó al principio solo a los plebeyos, pero más tarde a todo el pueblo. ${ }^{4}$

Por tanto, el referéndum está orientado a la confirmación de un acto del Ejecutivo, posee valor jurídico o busca la aprobación de transformaciones territoriales o políticas. En ocasiones lleva un pronunciamiento sobre la competencia de alguno de sus gobernantes.

Mientras, el plebiscito es el acto jurídico y político de aprobación, es decir, expresa la confianza del cuerpo electoral en un gobernante o sistema político. Es una modalidad participativa, pero entraña un gran riesgo de manipulación. Algunos expertos como Parodi ${ }^{5}$ afirman que siempre ha habido confusión entre los dos términos. Biscaretti ${ }^{6}$ manifiesta que el plebiscito se debería utilizar para cuestiones de carácter territorial y del gobierno, y el referéndum se reservaría para los actos normativos. Así mismo, Loewenstein ${ }^{7}$ considera que en cuestiones que no sean constitucionales o legislativas debería utilizarse el término plebiscito. Por último, según Rallo Lombarte, ${ }^{8}$ el referéndum permite que el pueblo intervenga directamente en la configuración de las leyes y en algunas de las decisiones políticas y el plebiscito es un derecho que se reconoce al cuerpo electoral para intervenir excepcionalmente en actos políticos o constitucionales. En este sentido, confirma el coautor del presente trabajo, se trataría de términos sinónimos, aunque históricamente se empleara la voz "plebiscito" de forma peyorativa. ${ }^{9}$

Salvo la época de Napoleón en Francia, cuando el plebiscito estaba reservado a las consultas sobre personas y hechos, no hay distinciones significativas entre los términos referéndum y plebiscito, aunque nuestra Constitución ha optado por el primero, en la medida en que el plebiscito conserva ciertas adherencias totalitarias que han desembocado en su utilización para aludir a aquel referéndum que no

Real Academia de la Lengua Española, "Plebiscito" en Diccionario de la lengua española, https://dle.rae. es/?id=TOBzlgN (acceso mayo 18, 2018).

5 Jean Luc Parodi, La politique (París: Hachette, 1972), 395 y ss.

6 Paolo Biscaretti di Ruffia, Derecho constitucional (Madrid: Tecnos, 1965), 425 y ss.

7 Karl Loewenstein, Teoría de la Constitución (Barcelona: Ariel, 2018), 331 y ss.

8 Artemi Rallo Lombarte, Garantías electorales y Constitución (Madrid: Centro de Estudios Políticos y Constitucionales, 1997), 32-33.

9 José Luis López González, El referéndum en el sistema español de participación política (Valencia: Universidad Politécnica de Valencia, 2005), 9. 
reúne las debidas condiciones democráticas o para designar un régimen autoritario que se apoya en este instituto (cesarismo plebiscitario). ${ }^{10}$

En el presente artículo se apuesta por un empleo equilibrado, prudente y sensato del referéndum como modalidad integrante del sistema español de participación política. Esa es, en nuestro criterio, su razón de ser en la Constitución española. Se trata de hacer realidad una técnica de adopción de decisiones de carácter complementario en el marco de un Estado constitucional representativo. Constituiría un error imperdonable intentar contraponer o enfrentar el referéndum al normal funcionamiento de los poderes constituidos o, lo que es lo mismo, suplantar, mediante su uso inadecuado, las competencias y atribuciones propias de los órganos constitucionales del Estado. Al contrario: en el sistema constitucional español, el referéndum asume la función de complemento racionalizado y limitado de la democracia representativa.

\section{El referéndum como modalidad del sistema español de participación política: ejercicio responsable de la ciudadanía democrática}

No resulta exagerado definir la última década como un período convulso. Como bien se sabe, no se trata de un problema que se circunscriba a España, sino que su dimensión excede cualquier análisis nacional y continental, pues nos encontramos ante una crisis económica globalizada, generadora de una fuerte desafección hacia los gobernantes y la política en general. La llegada de las tecnologías a nuestras vidas hace que las noticias (incluidos los troles) sean de consumo instantáneo — sobre todo por medio de la red-y que las informaciones y los mensajes de WhatsApp, Twitter, Instagram, Facebook y blogs, entre otros, influyan en la opinión del ciudadano.

A modo de ejemplo, una consulta del siguiente tenor literal “¿Por cuál partido votaría usted en este momento?" tendrá una respuesta sin duda condicionada por esas noticias, verdaderas o falsas. Esta realidad habrá de tomarse en consideración a la hora de analizar los resultados de la encuesta.

10 Puede verse Loewenstein, Teoría de la Constitución, 80; López González, El referéndum en el sistema español de participación política, 8-9. En sentido similar, José Luis García Guerrero, "Teorías de la representación política directa y partidos políticos", en Derecho constitucional comparado, dir. Diego López Garrido et al. (Valencia: Tirant lo Blanch, 2017), 498. 
En realidad, ¿están los ciudadanos informados? ¿Disponen de los conocimientos necesarios ajustados a derecho para intervenir en los medios de comunicación y las redes sociales con opiniones que no son exactas o están fuera de contexto y, por consiguiente, sesgadas? En suma, se ha generado una desconfianza ante los partidos políticos y sus representantes. Así lo han puesto de manifiesto los autores del presente estudio doctrinal en una publicación anterior:

El concepto de democracia vive momentos difíciles que tienen que ver con las malas prácticas, la corrupción y el condicionamiento de la decisión pública por fuerzas incontroladas que obedecen al nuevo orden (o, más bien, desorden) económico global. De manera gráfica y deliberadamente exagerada, una vez perdida su verdadera libertad de decidir, los políticos tienden a asemejarse a lo que serían meras marionetas movidas por su propia vanidad. De algún modo, los Gobiernos democráticos de Occidente "escriben sus leyes al dictado". ${ }^{11}$

En efecto, Loewenstein ${ }^{12}$ se cuestionaba si un ciudadano medio podría emitir juicios razonables sobre temas que no son de su conocimiento o se dejaría llevar por las emociones. Además, afirmó:

[... el el gobierno de crisis, cualquiera que sea su base jurídica, afecta seriamente al desarrollo normal del proceso político y suspende, según sea su conformación, el funcionamiento de los normales controles interórganos en favor del detentador del poder ejecutivo y a costa del legislativo. Pero dado que la situación de crisis en el mundo será de duración, con toda probabilidad, la democracia constitucional tendrá que resignarse y convivir con el gobierno de crisis.

Antes de continuar ha de hacerse un breve repaso de los orígenes de la institución del referéndum. Conviene aclarar que, en primer lugar, se empleó el término plebiscito en la República romana mediante el denominado "decreto de la plebe" o "plebiscito romano", que era convocado por su tribuno ${ }^{13}$ y votado en comicios.

11 José Luis López González y Montserrat de Santiago, "Significado y función del derecho de sufragio en la actividad electoral en un Estado democrático", Novum Jus 12, núm. 1 (2018): 61.

12 Loewenstein, Teoría de la Constitución, 181 y 293.

13 "2. m. Cada uno de los magistrados que elegía el pueblo romano reunido en tribus, y tenían facultad de poner el veto a las resoluciones del Senado y de proponer plebiscitos". Real Academia de la Lengua Española, "Tribuno" en Diccionario de la lengua española, http://dle.rae.es/?id=acLJm5b (acceso mayo 18, 2018).

También pueden verse: Jean Jacques Rousseau, El contrato social (Barcelona: Atalaya, 1988), 119; Loewenstein, Teoría de la Constitución, 156 y ss.; López González, El referéndum en el sistema español de participación politica, 13 y ss. 
De la misma manera, en la Baja Edad Media, las decisiones denominadas dietas medievales eran sometidas ad referendum y se debatían en Asamblea.

La democracia directa se encuentra vinculada al modelo de comunidades políticas que se experimentaban en las polis griegas, donde las decisiones se adoptaban en las plazas públicas. Un planteamiento idílico generalizado lleva a olvidar que en esas votaciones no participaban las mujeres, los esclavos, los forasteros o las clases de poder adquisitivo bajo; por tanto, sus derechos no estaban representados. Del mismo modo, en los municipios de la Europa medieval operaban mecanismos de participación directa muy rudimentarios que se fueron extinguiendo.

La Revolución del Parlamento, en la Inglaterra del siglo XVII, propició la caída del poder monárquico y su relevo por el sistema de participación indirecta mediante el Parlamento. En realidad, debido a la complejidad de las sociedades actuales resulta muy difícil articular un sistema democrático solo a partir de una sucesión continuada de decisiones directas por parte del electorado. ${ }^{14}$ En idéntica línea argumental apuntaba Loewenstein: "En la moderna sociedad de masas, el único medio practicable para hacer participar a los destinatarios del poder en el proceso político es la técnica de representación, que en un principio fue meramente simbólica y más tarde real". ${ }^{15}$

En este escenario, como recuerda Aragón Reyes, también se puede ejercer la democracia directa mediante la actividad electoral, pues el derecho al sufragio no está conectado en exclusiva con la democracia representativa. Sostiene el autor:

[...] las dificultades prácticas y los graves inconvenientes teóricos de la democracia directa han originado que ésta no pueda verse como una alternativa a la democracia representativa sino, todo lo más, como su complemento [...]. En tal sentido, conserva toda su vigencia aquella afirmación de Kelsen, hecha en el siglo pasado, de que no hay más democracia posible que la democracia representativa. ${ }^{16}$

14 Manuel Aragón Reyes y José Luis López González, "Plebiscito" en Diccionario electoral tomo II (San José: Instituto Interamericano de Derechos Humanos, 2000), 981-982.

15 Loewenstein, Teoría de la Constitución, 151.

16 Manuel Aragón Reyes, Estudios de derecho constitucional (Madrid: Centro de Estudios Políticos y Constitucionales, 2013), 522-523. 
Para Rousseau, la soberanía no puede estar representada ni enajenada pues, en definitiva, "consiste esencialmente en la voluntad general, y la voluntad no se representa; es la misma o es otra; no hay término medio". ${ }^{17}$ En concreto, según el pensamiento de Rousseau, la participación del pueblo debe ser activa y continuada, para que pueda considerarse condición y garantía de la libertad de cada ciudadano —esto es, de su "autodeterminación" — y así evitar los abusos de poder de los gobernantes.

En esta etapa predominan dos modelos de participación: el defendido por Montesquieu y el formulado por Rousseau; así surgen tensiones entre los defensores de la democracia representativa y los de la democracia directa. Este período revolucionario francés permite que se consagre el principio referendario y quede recogido en la Constitución de 1793 y, por ende, que triunfe la forma de participación indirecta, aunque en la Constitución de 1795, de carácter conservador, se restablecieron los principios de democracia representativa. Fue en el siglo XVIII cuando se promovieron los debates doctrinales sobre la participación directa de los ciudadanos y la elaboración de las declaraciones de derechos y de la Constitución. Empero, el referéndum no se consolidó, a excepción de Suiza, que lo incorporó junto a la iniciativa legislativa popular de la Constitución de 1874 y algunos estados de Estados Unidos de América. Asimismo, en el marco del Estado liberal representativo, ya en el siglo XIX se incorporó en Europa, con una significación especial en la Confederación Helvética, al modelo organizativo democrático. ${ }^{18}$

En el siglo XX, el referéndum emergió en la Constitución de Alemania de 1919 y en la de Austria de 1920, pero flaqueaba en las Constituciones de la democracia parlamentaria en la Europa de entreguerras, debido a las corrientes totalitarias: por un lado, la extrema derecha y por el otro, la extrema izquierda. Apremiaba establecer mecanismos de democracia directa, para paliar las crisis por las que estaban pasando los sistemas parlamentarios. En ese contexto, los expertos de la época buscaban procedimientos de corrección para revitalizar los esquemas de la democracia parlamentaria. En estos regímenes antidemocráticos consiguieron

17 Rousseau, El contrato social, 333.

18 Puede verse, por ejemplo, Pedro de Vega García, La reforma constitucional y la problemática del poder constituyente (Madrid: Tecnos, 1985), 102 y ss.; López González, El referéndum en el sistema español de participación política, 14 y ss.; Susana Sánchez Ferro, "El referéndum de independencia escocés: ¿Evolución o revolución del derecho constitucional británico?", Revista Española de Derecho Constitucional, núm. 103 (enero-abril 2015): 111-156; Eva Sáenz Royo, "La regulación y la práctica del referéndum en Suiza", Revista de Estudios Políticos, núm. 171 (2016): 71-104; Jorge San Vicente Feduchi, "Referéndum", Eunomía, núm. 14 (2018): 276 y ss. 
distorsionar el sentido del referéndum por medio de manipulaciones y propaganda, hasta que dichosamente fueron derrotados. Por ejemplo, algunos países europeos en la segunda posguerra acudieron al referéndum como opción para regresar a las Constituciones vigentes antes de la ocupación alemana, como alternativa a procesos constituyentes o para manifestar la preferencia por la monarquía o la república, como ocurrió en Bélgica y en Italia. Otro partidario de la institución del referéndum de forma autoritaria y mediatizada fue el general de Gaulle en Francia. ${ }^{19}$

Nuestro país no tiene precedentes históricos de referéndum, con la salvedad de la Constitución Republicana de 1931, que hacía referencia en su Artículo 12 a la posibilidad de un plebiscito para la aprobación del Estatuto de la región autónoma, con unas condiciones explícitas: que lo propusieran casi todos los Ayuntamientos de los que se componía la región o los municipios que comprendieran las dos terceras partes del censo. En segundo lugar, su aceptación sería igualmente aprobada por las dos terceras partes del censo electoral, según el procedimiento estipulado en la Ley electoral. Si el mencionado plebiscito arrojara un resultado negativo, no se podría repetirlo sino hasta después de cinco años.

Por otra parte, cuando alude al referéndum en el Artículo 66 de la Constitución de 1931, exponía:

El pueblo podrá atraer a su decisión mediante "referéndum" las leyes votadas por las Cortes. Bastará, para ello, que lo solicite el 15 por 100 del Cuerpo electoral.

No serán objeto de este recurso la Constitución, las leyes complementarias de la misma, las de ratificación de Convenios internacionales inscritos en la Sociedad de las Naciones, los Estatutos regionales, ni las leyes tributarias.

El pueblo podrá asimismo, ejerciendo el derecho de iniciativa, presentar a las Cortes una proposición de ley, siempre que lo pida, por lo menos, el 15 por 100 de los electores.

19 Puede verse López González, El referéndum en el sistema español de participación política, 15 y ss. Un análisis del referéndum en perspectiva comparada puede verse en García Guerrero, "Teorías de la representación política directa y partidos políticos", 498-503. 
Una ley especial regulará el procedimiento y las garantías del "referéndum" y de la iniciativa popular. ${ }^{20}$

En la Constitución de la II República se vislumbra el referéndum legislativo y la iniciativa legislativa popular. No debemos tener en cuenta los referendos de la España franquista, que fueron inequívocamente una manera de legitimar la dictadura y que anulan el significado del referéndum como institución de la democracia directa. El primero se llevó a cabo el 6 de julio de 1947, para aprobar la Ley de sucesión del Estado. El segundo tuvo lugar el 14 de diciembre de 1966, para aprobar la nueva Ley Orgánica y separar los cargos del jefe de Estado y del presidente del Gobierno.

En cuanto a la clasificación de los referendos, apostamos por la que ya ofrecía el coautor del presente artículo, ${ }^{21}$ que coincide con el criterio mayoritario en la doctrina y, en nuestro concepto, contribuye efectivamente a su comprensión como forma de participación democrática directa.

Dicha tipología lo clasifica así: por una parte, de ámbito territorial, que los diferencia entre nacionales y territoriales; por otra, en razón a la necesidad o no de su convocatoria, distingue el obligatorio del facultativo (Tabla 1). Así lo expone Cruz Villalón:

El derecho a convocar, si se considera oportuno, el referéndum, inexistente, por definición, en el caso del catalogado como obligatorio, se convierte así en el denominado referéndum facultativo. El referéndum obligatorio, por el contrario, se configura normalmente como un fenómeno ocasional, y ello pese a la trascendencia que suele acompañar a esta modalidad de consulta popular. En efecto, la misma tiene lugar en casos como, por ejemplo, la reforma de la Constitución. Por el contrario, el derecho de iniciativa del referéndum (aplicable a las consultas referendarias de naturaleza facultativa) aparece y funciona como un recurso permanentemente esgrimible en el juego de las relaciones de poder entre los supremos órganos del Estado. ${ }^{22}$

20 España, Constitución de la República Española (Madrid, 9 de diciembre de 1931), art. 66. Se puede consultar en la página del Congreso de los Diputados: http://www.congreso.es/docu/constituciones/1931/1931_cd.pdf

21 López González, El referéndum en el sistema español de participación política, 35 y ss.; "El referéndum nacional consultivo sobre decisiones políticas de especial trascendencia en el ordenamiento constitucional español" en Libro homenaje a D. Íñigo Cavero Lataillade, coord. José Peña González (Valencia: Tirant lo Blanch, 2005), 35 y ss.

22 Pedro Cruz Villalón, "El referéndum consultivo como modelo de racionalización constitucional", Revista de Estudios Políticos, núm. 13 (1980): 146. 
Tabla 1- Tipología de la institución del referéndum

\begin{tabular}{|c|c|c|}
\hline \multirow[t]{4}{*}{ Ámbito territorial } & \multirow[t]{2}{*}{ Nacionales } & Referéndem Consultivo del Art. $92 \mathrm{CE}$ \\
\hline & & $\begin{array}{l}\text { Referendos de Reforma Constitucional de los Art. } \\
167.3 \text { y } 168.3 \text { CE }\end{array}$ \\
\hline & \multirow[t]{2}{*}{ Territeoriales } & Referendos Regionales \\
\hline & & $\begin{array}{l}\text { Reforma de los Estatutor de Autonomía, conforme } \\
\text { al Art. 152.2. CE }\end{array}$ \\
\hline \multirow[t]{3}{*}{ Caráter } & \multirow[t]{2}{*}{ Obligatorios } & Mandato Constitucional \\
\hline & & $\begin{array}{l}\text { La Consulta no depende de ningún poder público } \\
\text { o de una fracción del cuerpo electoral. }\end{array}$ \\
\hline & Facultativos & $\begin{array}{l}\text { Cuando se convoca a instancia del órgano o de } \\
\text { determinado porcentaje de sus miembros que estén } \\
\text { legitimados para ello. }\end{array}$ \\
\hline
\end{tabular}

Fuente: elaboración propia con base en López González, El referéndum en el sistema español de participación politica, 35.

Se trata, como ha escrito Pedro de Vega ${ }^{23}$ de una institución con la cual se pretende hacer realidad una técnica de adopción de decisiones complementaria, en el marco de un Estado constitucional básicamente representativo.

El referéndum no persigue, en modo alguno:

[...] suplantar los mecanismos y el ejercicio normal de los poderes constituidos. Su actuación no implica el asalto al Estado constitucional, sino que, al contrario, significa una complementación del sistema de los "checks and balances", de los frenos y contrapesos que más genuinamente lo definen y caracterizan. Con el referéndum [...] se ratifica o no un acto del poder constituido, lo que no supone menoscabar sus competencias y atribuciones. ${ }^{24}$

En definitiva, el referéndum asume la función de complemento de la democracia representativa. Así pues:

[...] dada la general y expresa atribución de la potestad legislativa a las Cortes Generales (así como a las Asambleas Legislativas de las Comunidades Autónomas), hay que sostener que en nuestro Estado democrático la democracia

23 De Vega García, La reforma constitucional, 122-123.

24 De Vega García, La reforma constitucional, 122-123. También puede verse: Joan Oliver Araujo, "El referéndum en el sistema constitucional español", Revista de Derecho Político, núm. 29, (1989): 133 y ss. 
representativa es la regla general y el referéndum la excepción, por lo que las normas que lo prevén han de ser interpretadas restrictivamente..$^{25}$

\section{El referéndum del Artículo 92 CE como actividad electoral: convocatoria y procedimiento}

La Ley Orgánica 2/1980 regula en su Artículo 2 las modalidades y fases del referéndum que conlleva o conduce a la celebración de la consulta popular con tres momentos clave: la propuesta, la autorización y la convocatoria. En el Artículo 4.1 de la mencionada Ley podría verse el procedimiento del referéndum alterado cuando las condiciones políticas en todo el territorio español no sean las óptimas para su celebración.

La participación de los ciudadanos mediante el referéndum no solo constituye una actividad electoral que conlleva el reconocimiento y la protección jurisdiccional al derecho al sufragio. En democracia, el ciudadano tiene la obligación de informarse y con esa información ha de mantener una posición crítica ante el poder que le permita, entre otros modos de participación, efectuar de forma consciente y responsable el control temporal del ejercicio del poder al que está llamado en cada convocatoria electoral.

Ejercer el derecho de sufragio resulta imprescindible. El referéndum está reconocido como fórmula de la democracia directa, que consiste, en opinión de Correas, en consultar a todo el cuerpo electoral, con el objetivo de que se pronuncie sobre las decisiones políticas o los textos a aprobar. ${ }^{26}$ La competencia es exclusiva del Estado. El rey convoca la consulta mediante real decreto, que se ha acordado en el Consejo de Ministros y refrendado por su presidente, esto es, el derecho del pueblo a intervenir directamente en el proceso de aprobación de las leyes o en la adopción de ciertas decisiones políticas. ${ }^{27}$

25 Manuel Aragón Reyes, "La democracia constitucional” en La experiencia constitucional (1978-2000), coord. Gumersindo Trujillo Fernández et al. (Madrid: Centro de Estudios Políticos y Constitucionales, 2000), 34.

26 Irene Correas Sosa, "Los derechos de participación política" en Lecciones de derecho constitucional, coord. María Isabel Álvarez Vélez (Valencia: Tirant lo Blanch, 2018), 451 y ss.

27 Puede consultarse con mayor amplitud en la investigación inicial llevada a cabo para la defensa del trabajo de fin de grado (TFG) realizado por la coautora y dirigido por el profesor doctor José Luis López González. 
Antes de seguir avanzando ha de repasarse, mediante un cuadro comparativo (Tabla 2), cómo se establecía el sufragio desde el Estatuto de Bayona, en 1808, hasta la Constitución de 1978, hoy vigente.

Tabla 2. El sufragio en España desde el Estatuto de Bayona hasta la actualidad

\begin{tabular}{|l|l|}
\hline Constitución/Estatuto/Proyecto & Sufragio (elector y voto) \\
\hline Estatuto de Bayona, 1808 & Indirecto para elección de Diputados provincias \\
\hline Constitución, 1812 & $\begin{array}{l}\text { Sufragio activo en elección de Diputados provincias, en } \\
\text { Juntas Electorales y de partido. Sufragio pasivo: censitario. } \\
\text { Para ser Diputado se ha de ser varón, mayor de } 30 \text { años } \\
\text { y disponer de un mínimo nivel de rentas. }\end{array}$ \\
\hline Estatuto Real 1834 & Sufragio Censitario. Se reguló por decreto. \\
\hline Constitución de la Monarquía Española, 1837 & $\begin{array}{l}\text { Sufragio activo directo y censatario. Sufragio pasivo } \\
\text { censitario. }\end{array}$ \\
\hline Constitución, 1845 & $\begin{array}{l}\text { Senado: censitario (nobles, clero, militar). Congreso; es } \\
\text { directo y censitario; los Diputados son nombrados por } \\
\text { la Junta electoral conforme a la Ley. }\end{array}$ \\
\hline Proyecto Constitucional, 1852 (Bravo Murillo) & $\begin{array}{l}\text { Senadores: natos, hereditarios y vitalicios; los Diputados } \\
\text { por Junta Electoral. }\end{array}$ \\
\hline Constitución no promulgada, 1856 & $\begin{array}{l}\text { Senado: censitario. Congreso es de elecciónj directya } \\
\text { por provincias. }\end{array}$ \\
\hline Constitución, 1869 & $\begin{array}{l}\text { Senado: activo, universal e indirecto. Congreso: sufragio } \\
\text { pasivo, altos cargos, sufragios universal maculino. }\end{array}$ \\
\hline Constitución, 1873 & $\begin{array}{l}\text { Senado: elegidos por los Palamentos de los Estados. } \\
\text { Congreso: universal y directo. }\end{array}$ \\
\hline Constitución, 1876 & $\begin{array}{l}\text { Senado: sufragio activo, censitario, estamental. Congreso: } \\
\text { remite Ley Censitario hasta 1890. }\end{array}$ \\
\hline Constitución, 1931 & $\begin{array}{l}\text { Sí, universal, masculino y femenino desde 1933. Libre, } \\
\text { directo y secreto. }\end{array}$ \\
\hline Constitución, 1978 & Sí, universal, masculino y femenino, libre, directo y secreto. \\
\hline
\end{tabular}

Fuente: elaboración propia.

No resulta exagerado manifestar que, sin elecciones, no hay democracia. En la actualidad se constata una profunda desafección de la ciudadanía respecto a los partidos políticos. Hoy más que nunca, en ese marco, ha de recordarse la trascendencia de ejercer nuestro derecho de sufragio meditado e informado, ya que la participación debe ser un pilar de todo edificio democrático, además de un instrumento para elegir a nuestros representantes. En ocasiones, un voto de castigo, para propiciar el cambio o para la renovación constructiva de un partido, es imprescindible. Una 
ciudadanía que se considere democrática y avanzada debe tener una decidida vocación de participación activa como deber cívico, materializado en el ejercicio del derecho de sufragio. Para ello, debe estar bien informado, implicarse y formar parte del tejido asociativo.

La participación nunca generaría un perjuicio para la democracia; sin embargo, la abstención total imposibilitaría la continuidad institucional, por lo que en Bélgica incluso es sancionada. ${ }^{28}$

En España y en la mayoría de los países iberoamericanos el grado de asociacionismo (incluidos sindicatos y partidos políticos) es insignificante, si lo comparamos con el activismo y las asociaciones del mundo anglosajón. ${ }^{29}$

Ejercer un derecho fundamental como la participación equivaldría a abrir pequeñas brechas que terminarían derribando los muros del desconcierto y el descrédito de los políticos.

En marcado tono crítico, Loewenstein escribe: "[...] siendo la naturaleza humana como es, no cabe esperar que el detentador o los detentadores del poder sean capaces, por autolimitación voluntaria, de liberar a los destinatarios del poder y a sí mismos del trágico abuso del poder". ${ }^{30}$

Otra interesante definición es la que formula el profesor Oliver Araujo. En su criterio, el referéndum es "uno de los mecanismos de participación directa del ciudadano en la vida política, consiste en formular una pregunta al cuerpo electoral para que éste se pronuncie, con un sí o un no, sobre la misma, sin ningún tipo de intermediarios". ${ }^{31}$ Por ende, en el sistema de participación política configurado en la Constitución española los ciudadanos gobiernan por medio de sus representantes; se trata entonces de una forma indirecta y por ello no intervienen en la discusión de las leyes.

La Constitución española consagra tres modalidades de referéndum: consultivo, constituyente y autonómico (Tabla 3).

28 Puede verse en una investigación inicial llevada a cabo para la defensa del TFG realizado por la coautora y dirigido por el profesor doctor José Luis López González.

29 López González y De Santiago, "Significado y función del derecho de sufragio", 78.

30 Loewenstein, Teoría de la Constitución, 149.

31 Joan Oliver Araujo, "El referéndum en el sistema constitucional español", Cuadernos de la Facultad de Derecho, núm. 15 (1986): 97. 


\subsection{Referéndum consultivo (CE, art. 92)}

Requiere autorización del Congreso de los Diputados por mayoría absoluta, a solicitud del presidente del Gobierno. La solicitud deberá contener los términos exactos de la consulta.

\subsection{Referéndum constituyente (CE, arts. 167 y 168 y LO 2/1980, art. 7)}

Está previsto en caso de reforma parcial o total de la Constitución. Las Cortes Generales comunicarán previamente al presidente del Gobierno el proyecto de reforma aprobado, que constituirá el objeto de la ratificación popular.

\subsection{Referéndum autonómico}

Tiene tres supuestos:

— Iniciativa autonómica (CE, art. 151.1 y LO 2/1980, art. 8).

- Aprobación por referéndum de un estatuto de autonomía (CE, arts. 2, 5 y 151.2, 3 y LO 2/1980, art. 9).

- Modificación de estatutos de autonomía (CE, art. 152.2 CE y LO 2/1980, art. 10).

Desde que se inauguró el actual período democrático, se han convocado cuatro referendos estatales: i) el de la Ley para la reforma política, en 1976; ii) en 1978, el de ratificación de la Constitución; iii) el relativo a la permanencia o no de España en la OTAN, que tuvo lugar en 1986, y iv) el que tenía como finalidad la aprobación del Proyecto de tratado de una Constitución para Europa, celebrado en 2005. En definitiva, el referéndum es un modo de participación complementaria y plenamente compatible con la democracia representativa. ${ }^{32}$

32 Idéntica posición se mantenía en el trabajo de fin de grado realizado por la coautora bajo la dirección del profesor doctor José Luis López González. 
Tabla 3. Modalidades de referéndum conforme a los Artículos 92, 167 y 168 de la Constitución

\begin{tabular}{|c|c|}
\hline $\begin{array}{l}\text { Referéndum Facultativo Consultivo } \\
\text { Art. } 92\end{array}$ & $\begin{array}{l}\text { 1. Las decisiones políticas de especial trascendencia podrán ser } \\
\text { sometidas a referéndúm consultivo de todos los ciudadanos. } \\
\text { 2. El referéndum será convocado por el Rey, mediante propuesta del } \\
\text { Presidente del Gobierno, previamente autorizada por el Congreso } \\
\text { de los Diputados } \\
\text { 3. Una Ley orgánica regulará las condiciones y el procedimiento } \\
\text { de las distintas modalidades de referéndum previstas en esta } \\
\text { Constitución. }\end{array}$ \\
\hline $\begin{array}{l}\text { Referéndum Facultativo Con } \\
\text { stituyente Art. } 167 \text { CE }\end{array}$ & $\begin{array}{l}\text { 1. Aprobación de la reforma por mayoría de tres quintos del Con- } \\
\text { greso y del Senado. } \\
\text { 2. Si hay desacuerdo entre las Cámaras, creación de una Comisión } \\
\text { de composición paritaria de diputados y de senadores. } \\
\text { 3. Procedimiento especial para solucionar un nuevo desacuerdo entre } \\
\text { las Cámaras sobre el texto elaborado por la Comisión paritaria. } \\
\text { 4. Ratificación de la reforma por referéndum, sólo en el caso de que } \\
\text { sea solicitado por décima parte de los miembros de cualquiera } \\
\text { de las Cámaras. }\end{array}$ \\
\hline $\begin{array}{l}\text { Referéndum Obligatorio Con } \\
\text { stituyente Art. } 168\end{array}$ & $\begin{array}{l}\text { 1. Cuando se propusiere la revisión total de la Constitución o una } \\
\text { parcial que afecte al Título preliminar, al Capítulo segundo, Sección } \\
\text { primera del Título I, o al Título II, se procederá a la aprobación } \\
\text { del principio por mayoría de dos tercios de cada Cámara, y a la } \\
\text { disolución inmediata de las Cortes. } \\
\text { 2. Las Cámaras elegidas deberán ratificar la decisión y proceder al } \\
\text { estudio del nuevo texto constitucional, que deberá ser aprobado } \\
\text { por mayoría de dos tercios de ambas Cámaras. } \\
\text { 3. Aprobada la reforma por las Cortes Generales, será sometida a } \\
\text { referéndum para su ratificación. }\end{array}$ \\
\hline
\end{tabular}

Fuente: elaboración propia.

Ya en un momento anterior, Tierney prevenía acerca de las muy sensibles disfunciones potenciales que acompañan a la institución del referéndum y que pueden compendiarse en tres aspectos: i) el control de las élites en los procesos, que implica alta probabilidad de la manipulación de los resultados; ii) la notable alteración de la finalidad de la consulta, que desvirtúa su sentido; de tal suerte, en lugar de usarse para dialogar, se acaba transformado en un instrumento perverso para asentar y consolidar prejuicios, y iii) no se tienen en cuenta los intereses de sectores alejados de los focos mediáticos y, en particular, los propios de las minorías a las que, en principio, podría servir como modalidad de participación política directa. ${ }^{33}$

33 Stephen Tierney, Constitutional Referendums. The Theory and Practice of Republican Deliberation (Oxford: Oxford Constitutional Theory, 2012), 23 y ss. 


\section{Las "decisiones políticas de especial trascendencia": ¿Actos o también normas? ¿Es vinculante el resultado del referéndum?}

El sistema constitucional español ha configurado diferentes posibilidades de participación popular vía referéndum y es aquel sobre "decisiones políticas de especial trascendencia" una modalidad de notable calado, ya que en nuestro sistema constitucional predomina la participación por medio de representantes. El Artículo 92 CE plantea problemas jurídicos como la propia noción de referéndum de ámbito nacional y su vinculación con los principios democráticos, como ha puesto de relieve Aragón Reyes:

[...] al pueblo no se le confiere la sanción o ratificación de la decisión, sino sólo el veto. La consulta es facultativa, claro está, pero vinculante. Su resultado negativo impide (no puede un órgano del Estado actuar frente al veto de la voluntad popular formalmente expresado) que la decisión pueda adoptarse. Su resultado positivo no dota por sí solo de eficacia jurídica a la decisión, puesto que ha de ser "ratificada", adoptada, después (eso sí, necesariamente) por el órgano estatal competente para ello. ${ }^{34}$

En otras palabras, la consulta al pueblo no delega por sí misma la competencia atribuida al órgano decisorio del Estado correspondiente, como lo prueba el propio carácter facultativo de la convocatoria. En consecuencia, al poder público no puede sustituirlo el pueblo. Por el contrario, es el poder público el que tiene encomendada la ratificación normativa de lo decidido en referéndum. ${ }^{35}$ Para Santamaría Pastor, las decisiones políticas de especial trascendencia configuran una terminología incorrecta, poco operativa y con limitaciones evidentes, aunque se trata de un concepto jurídicamente indeterminado. ${ }^{36}$

Consultivo no es sinónimo de no vinculante, sino de no ratificador o sancionador. Lo que sí parece difícilmente discutible, más allá de cualquier regulación normativa,

34 Manuel Aragón Reyes, "La eficacia jurídica del principio democrático", Revista Española de Derecho Constitucional, núm. 24 (1988): 44.

35 López González y De Santiago, "Significado y función del derecho de sufragio", 70. López González, "El referéndum nacional consultivo sobre decisiones políticas de especial trascendencia en el ordenamiento constitucional español", 425.

36 Juan Alfonso Santamaría Pastor, "Comentario al artículo 92 de la Constitución Española de 1978" en Comentarios a la Constitución, coord. Fernando Garrido Falla (Madrid: Civitas, 2001), 1453 y ss. 
es que el resultado del referéndum nacional debería ser siempre vinculante. El referéndum es un modo de participación complementaria, compatible con la democracia representativa.

Cabe diferenciar entre una consulta y un referéndum. Para Carrasco Durán:

[... el el punto de partida a la hora de trazar la línea que separa el referéndum de las demás formas de consulta debe ser la Constitución. Si las consultas son el término genérico para designar los instrumentos de participación directa que permiten a los ciudadanos expresar su opinión sobre asuntos de interés público, parece lógico entender que el referéndum designa un tipo singular de consulta, y que solo las consultas para las que la Constitución prevé la denominación de referéndum merecen tal consideración. ${ }^{37}$

Un precedente importante de esta modalidad de referéndum se encuentra en el sistema constitucional sueco, en el que, al igual que en el español, la técnica del referéndum es compatible con el funcionamiento del sistema parlamentario. En nuestro ordenamiento, el referéndum del Artículo 92 es una consulta de alcance nacional, desprendida del carácter extraordinario que entraña la modalidad de reforma constitucional.

En España, con la dictadura de Francisco Franco, que comprende el período de 1947 a 1966, se convocaron varios referendos, pero, como era previsible en aquella situación, no fueron libres y mucho menos democráticos. Como también suele acontecer en regímenes autoritarios de todo orden, constituyeron la excusa para tratar de legitimar, sin lograrlo, el poder de un dictador. Para Dewey:

Probablemente, no hay antítesis más frecuente realizada en la discusión moral que la existente entre el actuar "por principios" y por "interés". Actuar por principios es actuar desinteresadamente, conforme a una ley general que está por encima de toda consideración personal. Actuar por interés es, según se dice, actuar egoístamente, teniendo a la vista el provecho personal. ${ }^{38}$

37 Manuel Carrasco Durán, "Referéndum versus consulta", Revista de Estudios Políticos, núm. 160 (abril-junio 2013): 17

38 John Dewey, Democracia y educación (Madrid: Morata, 2004), 292. 
Confirma Santamaría Pastor que sería inusitado que los órganos que tienen el poder de adoptar las decisiones sobre lo consultado lo hicieran al contrario de lo pronunciado, en parte o en su totalidad, por la voluntad popular. ${ }^{39}$

La opinión pública ha resultado ser compañera inseparable del viaje hacia la participación política plena. Ello implicará que las libertades democráticas de comunicación son lastradas por una economía capitalista como un marco que determina el discurso político y, por consiguiente, en ausencia de poderes efectivos, el político puede llegar a convertirse en una marioneta movida por su propia vanidad. Esto conlleva, por un lado, que las deudas de cada partido político, al margen de su color ideológico, condicionan el crédito electoral y fomentan un trato privilegiado a entidades financieras $y$, por otro, en unas nefastas consecuencias que son inmediatas, por ejemplo, la tendencia al pensamiento único influido por los medios.

En este entorno se acaba promoviendo la aparición de medios de comunicación "de partido" y la merma del ejercicio efectivo del pluralismo político, con el dominio de los consejos de administración de las empresas de comunicación por multinacionales y entidades financieras. Una solución, en el medio y largo plazo, podría llegar de la mano de un pacto educativo de amplio alcance, que cuente con el consenso de los partidos políticos principales y que favorezca la promoción de contenidos educativos relacionados con los principios democráticos y los valores constitucionales desde la educación primaria hasta la universidad.

Cabe preguntar si los mercados influyen en las decisiones políticas. En tal sentido, se incorpora a continuación una investigación reciente sobre las consultas realizadas en Escocia y en el Reino Unido. Tal referéndum pudo celebrarse porque, en dicho ordenamiento constitucional, la soberanía no reside en el pueblo, como ocurre en la mayoría de los Estados occidentales, sino en el Parlamento, por lo que fue suficiente con su aprobación mediante el aludido instrumento referendario. Estas consultas afectan la inversión privada, independientemente de su resultado final, como ha sido acreditado por la investigación de Azqueta, que demuestra que:

[...] aquellas empresas más limitadas financieramente también reducen la inversión más significativamente a consecuencia de la incertidumbre. [...] por lo tanto las implicaciones políticas resultantes de este estudio son importantes, especialmente si se tiene en cuenta el clima económico actual. Los referendos

39 Santamaría Pastor, "Comentario al artículo 92", 1453 y ss. 
se están convirtiendo en una herramienta popular, pero sus consecuencias, esencialmente en tanto fuente de incertidumbre, a menudo escapan al debate político. ${ }^{40}$

No obstante, por lo acontecido en los últimos meses con el brexit, no podemos decir que un referéndum sea portador, por sí mismo, de soluciones a los problemas de los ciudadanos. Tal vez si se consultara en estos momentos, los resultados no serían los mismos. Ha puesto de manifiesto Loewenstein:

Han pasado muchos siglos hasta que el hombre político ha aprendido que la sociedad justa, que le otorga y garantiza sus derechos individuales, depende de la existencia de límites impuestos a los detentadores del poder en el ejercicio de su poder, independientemente de si la legitimación de su dominio tiene fundamentos fácticos, religiosos o jurídicos [...]. La historia del constitucionalismo no es sino la búsqueda por el hombre político de las limitaciones al poder absoluto ejercido por los detentadores del poder, así como el esfuerzo de establecer una justificación espiritual, moral o ética de la autoridad, en lugar del sometimiento ciego a la voluntad de la autoridad existente. ${ }^{41}$

\section{Conclusiones}

Abordar la posición del referéndum y del resto de modalidades de participación política supone partir del concepto de dignidad de la persona, recogido en el Artículo 10.1 CE. La participación es un reconocimiento a la dimensión social de la persona; se trata de un modo de integración activa del sujeto en la sociedad con base en el derecho a la participación libre, plural y significativa amparado por nuestra norma suprema. La participación política ha de contar con el soporte imprescindible de una sociedad mínimamente vertebrada, sólida, justa y con equidad.

El referéndum ha de insertarse en un contexto necesaria y decididamente democrático. La democracia precisa de la libertad, materializada en un pluralismo político que se expresa en el Parlamento como parte esencial del proceso de adopción de las mejores decisiones, que son el producto natural de la deliberación ordenada, concertada y

Andrés Azqueta Gavaldón, “iAfectan los referendos a la inversión? La evidencia de Escocia”, El Periódico, Secc. Agenda económica, 24 de julio de 2018, http://agendapublica.elperiodico.com/afectan-los-referendos-a-la-inversion-la-evidencia-de-escocia/ (acceso mayo 18, 2018).

${ }^{41}$ Loewenstein, Teoría de la Constitución, 149-150. 
sistemática entre rivales políticos unidos en la leal defensa de la democracia y de los derechos fundamentales, a cuya preservación se orienta dicha forma de Estado.

El referéndum contemplado en el Artículo 92 CE es una consulta popular limitada y racionalizada, cuya utilización en circunstancias de normalidad no produce alteraciones en el esquema constitucional de distribución de poderes. En la convocatoria de esta consulta popular sobre decisiones políticas de especial trascendencia, el Gobierno suele contar con una mayoría favorable en el Congreso de los Diputados; por ende, la intervención parlamentaria en dicha convocatoria se dirige a posibilitar que la oposición pueda pronunciarse sobre la oportunidad o no del referéndum que se pretende convocar. Una solución que cabría contemplar para potenciar el control parlamentario en esta modalidad referendaria del Artículo $92 \mathrm{CE}$ consiste en la exigencia de una mayoría superior incluso a la absoluta (dos tercios, por ejemplo). Sin embargo, todo parece indicar que tal exigencia ha de descartarse, por cuanto una mayoría de dos tercios - superior, por tanto, a la prevista para la reforma de la Constitución por la vía del Artículo 167 CE— resulta desproporcionada.

En principio, la corrección de la Ley Orgánica sobre modalidades de referéndum podría suscitar ciertas dudas, al hacer necesario el acuerdo del Gobierno para expedir el decreto de convocatoria (art. 2.3), cuando la Constitución (art. 92.2) había atribuido solo al presidente del Gobierno la adopción de la iniciativa y no había contemplado la intervención del Gobierno. No obstante, en la medida en que el Legislador ha optado (entendemos que de modo razonable) porque todos los referendos se convoquen por real decreto, se hace imprescindible la actuación del Consejo de Ministros, único órgano capaz de emanar este tipo de actos (a excepción, que no es el caso, de los decretos organizativos del presidente del Gobierno, previstos en el art. 2.2.j) de la Ley del Gobierno). Lo que sucede es que este acuerdo del Consejo de Ministros dictando el decreto de convocatoria se configura, en este caso, como un acto debido (una competencia de obligatorio ejercicio). Una vez propuesto el referéndum por el presidente y autorizado por el Congreso de los Diputados, el Consejo de Ministros ha de adoptar necesariamente el decreto de convocatoria. Se trata, en definitiva, de un requisito formal.

El referéndum del Artículo 92 CE es una consulta facultativa, es decir, el Gobierno, en tanto órgano que tiene atribuida la convocatoria de la consulta, puede adoptar la decisión de especial trascendencia sin consultar previamente al pueblo. En cualquier caso, incluso aunque el Gobierno opte por convocar el referendo, la decisión política de especial trascendencia sobre la que se consulta al pueblo deberá encontrarse ya 
prefigurada. Por consiguiente, solo puede someterse a consulta popular un acto de voluntad manifestado y traducido en una posición ya configurada, en una postura definida sobre la que los ciudadanos habrán de tomar una decisión. Esto significa que el Gobierno, sin perjuicio del inexcusable pluralismo político y de la neutralidad electoral del poder público, ha de poner de manifiesto y explicar de manera suficiente su posición en relación con la cuestión sobre la que versa la consulta.

En la consulta popular sobre decisiones de especial trascendencia, prevista en el Artículo $92 \mathrm{CE}$, todo el peso de la propuesta recae sobre el presidente del Gobierno. Esta modalidad de referéndum posibilita que el presidente del Gobierno, con el apoyo de la mayoría parlamentaria afín, obtenga la consolidación de su posición política frente a la oposición. En cierto modo, la atribución exclusiva de la iniciativa para convocar el referéndum sobre decisiones de especial trascendencia al presidente del Gobierno (independientemente de que sea necesaria una deliberación previa en el Consejo de Ministros) desnaturaliza la función participativa que, en principio, cabría atribuir a esta consulta popular. Por lo anterior, el referéndum consultivo sobre decisiones políticas de especial trascendencia se configura, en mayor medida, como un instrumento eficaz para reforzar la legitimidad de la política del Gobierno en situaciones muy concretas que tengan una o varias de las siguientes características: i) que se trate de actos estatales de especial solemnidad o trascendencia; ii) que las alternativas que se contemplan ocasionen una acentuada división en la opinión pública, y iii) que la decisión que se ha de adoptar sea difícilmente reversible.

Aunque el término "elecciones" se conecta de inmediato con el de "representación", no queda agotado en este, ya que también existe actividad electoral en los referendos. En estos últimos hay derecho de sufragio activo, aunque no pasivo, claro está. Ahora bien, la condición de elector es común al votar para elegir representantes o para optar por el sí o el no en una consulta popular. Cuando el cuerpo electoral se pronuncia en referéndum no lo hace como poder constituyente; sin embargo, en cualquier modalidad de participación política, incluso la que aquí se analiza, no deja de ser la expresión de la voluntad del titular de la soberanía. De esta forma, el principio democrático exige que ese pronunciamiento popular en las urnas sea vinculante para los poderes públicos, pues no ha de olvidarse que en el referéndum existe actividad electoral, aunque de contenido diferente a la orientada a la elección de representantes. Si es indiscutible el carácter vinculante de la manifestación de la voluntad popular en la elección de representantes, no es sencillo modificar ese criterio en esta otra modalidad electoral. De modo análogo, no parece aconsejable interpretar el término "consultivo" del Artículo 92 CE como equivalente a "no 
vinculante", sino como sinónimo de "no ratificador" o "no sancionador", es decir, la decisión del pueblo en referéndum será vinculante, pero deberá ser formalizada por el órgano que convocó la consulta. En definitiva, la vigencia efectiva del principio democrático difícilmente sería compatible con la posibilidad de que un órgano del Estado pudiera actuar frente al veto de la voluntad popular manifestado en referéndum. Al fin y al cabo, en democracia, siempre que el electorado se pronuncia en las urnas no lo hace en concepto de recomendación o consejo, sino en el de orden o mandato de cumplimiento ineludible.

Ha de cuidarse la imprescindible afinidad entre la democracia representativa (la representación, en tanto modo de reconducir la pluralidad a la unidad por medio de la deliberación parlamentaria, es consustancial a la idea de Estado) y el referéndum como instrumento complementario, en determinados escenarios de participación democrática. La cláusula constitucional de Estado democrático exige la conjunción de ambos.

En los momentos actuales asistimos a un muy peligroso quiebre de la dimensión argumentativa de la política (o de la democracia deliberativa en tanto concepción liberal de la misma), esto es, del discurso racional adecuadamente argumentado. Ello guarda relación con un clima de degeneración de la moral pública en el que se produce un divorcio entre representantes políticos y ciudadanos, que contribuye a que tal desafección sea más pronunciada. En ese clima, en la oposición se habla de "principios" y en el Gobierno se justifica su incumplimiento por el mismo equipo político, al amparo de lo que se define como "responsabilidades". A nadie se le puede ocultar que el referéndum, en tanto forma alternativa de participación política, no está llamado a suplir esta carencia, aunque algunos, desde determinados planteamientos políticos muy localizados, se empeñen en sostener lo contrario, con argumentos de escaso vuelo conceptual.

Es preciso tomar en consideración las particularidades de cada sistema político, así como la riqueza de matices de cada situación a la que se pretenda aplicar un referéndum. ${ }^{42}$ Sería absurdo, como se apuntó con anterioridad, oponer el referéndum, en su condición de modalidad o especialidad del derecho constitucional de participación política, a la democracia representativa. Lo adecuado, en nuestro criterio, sería tratar de alcanzar fórmulas de equilibrio de las que resultaría beneficiada

42 El brexit es un claro ejemplo de lo que acontece cuando se procede a una convocatoria de referéndum precipitada, en la que el convocante no es capaz de ponderar las consecuencias negativas que para Reino Unido podría acarrear su salida de la Unión Europea. 
la propia cláusula constitucional de Estado democrático que abraza ambas formas de participación.

No ha de olvidarse la peligrosa dinámica generada por la combinación de una baja participación (en no pocos casos, los referendos no están sujetos a requisito alguno de quórum) con un resultado ajustado. La concurrencia de ambas circunstancias reduce la fiabilidad del resultado de la consulta, en términos de legitimidad. A ello hay que añadir enseñanzas prácticas como las derivadas del brexit (junio de 2016) y del referéndum escocés sobre la independencia (septiembre de 2014). Ambas experiencias tuvieron una influencia negativa en términos de disminución de la inversión económica privada a lo largo del proceso. Una consecuencia de naturaleza económica, que va más allá del debate político y que tal vez escapaba a las previsiones de los convocantes y, con mayor motivo, si cabe, a las de los electores.

El referéndum requiere condiciones previas e imprescindibles de transparencia e información, así como de la plena consciencia por parte del ciudadano sobre el significado, el carácter y las consecuencias de la opción elegida y apoyada con el voto. Una adecuada formación para el ejercicio de la ciudadanía constituye el mejor modo de prevenir que los referendos no se empleen para enmascarar plebiscitos de adhesión incondicional a figuras carismáticas o a siglas evocadoras de emociones y sentimientos, en lugar de ofrecer el oportuno escenario participativo a razones y evidencias en relación con el asunto sometido a consulta.

De las modalidades de referéndum previstas en la Constitución, la relativa a las decisiones políticas de especial trascendencia (CE, art. 92) es la más significativa, en la medida en que permite incorporar una técnica de participación directa a un sistema constitucional como el español, construido en sus perfiles esenciales con la participación por medio de representantes. En efecto, el denominado referéndum consultivo del Artículo 92 CE pretende hacer realidad una técnica de adopción de decisiones de carácter complementario en el marco de un Estado constitucional representativo. Por elemental que pueda parecer, no ha de olvidarse que el referéndum ha de ser un mecanismo de participación política compatible con la Constitución española de 1978 de la que forma parte. 


\section{Referencias}

Aragón Reyes, Manuel y José Luis López González. "Plebiscito" en Diccionario electoral tomo II. San José: Instituto Interamericano de Derechos Humanos, 2000.

Aragón Reyes, Manuel. "La democracia constitucional" en La experiencia constitucional (1978-2000), coordinado por Gumersindo Trujillo Fernández, Luis López Guerra y Pedro José González-Trevijano Sánchez, 27-40. Madrid: Centro de Estudios Políticos y Constitucionales, 2000.

Aragón Reyes, Manuel. "La eficacia jurídica del principio democrático". Revista Española de Derecho Constitucional, núm. 24 (1988): 9-46.

Aragón Reyes, Manuel. Estudios de derecho constitucional. Madrid: Centro de Estudios Políticos y Constitucionales, 2013.

Azqueta Gavaldón, Andrés. "¿Afectan los referendos a la inversión? La evidencia de Escocia".

El Periódico, Secc. Agenda económica, 24 de julio de 2018. http://agendapublica. elperiodico.com/afectan-los-referendos-a-la-inversion-la-evidencia-de-escocia/ (acceso mayo 18, 2018).

Biscaretti di Ruffia, Paolo. Derecho constitucional. Madrid: Tecnos, 1965.

Carrasco Durán, Manuel. "Referéndum versus consulta". Revista de Estudios Políticos, núm. 160 (abril-junio 2013): 13-41.

Correas Sosa, Irene. "Los derechos de participación política" en Lecciones de derecho constitucional, coordinado por María Isabel Álvarez Vélez, 451-467. Valencia: Tirant lo Blanch, 2018.

Cruz Villalón, Pedro. "El referéndum consultivo como modelo de racionalización constitucional". Revista de Estudios Políticos, núm. 13 (1980): 145-168.

De Vega García, Pedro. La reforma constitucional y la problemática del poder constituyente. Madrid: Tecnos, 1985.

Dewey, John. Democracia y educación. Madrid: Morata, 2004.

España. Constitución de la República Española. Madrid, 9 de diciembre de 1931.

García Guerrero, José Luis. "Teorías de la representación política directa y partidos políticos", en Derecho constitucional comparado, dirigido por Diego López Garrido, Marcos Francisco Massó Garrote y Lucio Pergoraro, 487-533. Valencia: Tirant lo Blanch, 2017.

Loewenstein, Karl. Teoría de la Constitución. Barcelona: Ariel, 2018.

López González, José Luis y Montserrat de Santiago. "Significado y función del derecho de sufragio en la actividad electoral en un Estado democrático". Novum Jus 12, núm. 1 (2018): 59-82.

López González, José Luis. "El referéndum nacional consultivo sobre decisiones políticas de especial trascendencia en el ordenamiento constitucional español" en Libro homenaje 
a D. Ínigo Cavero Lataillade, coordinado por José Peña González, 415-425. Valencia: Tirant lo Blanch, 2005.

López González, José Luis. El referéndum en el sistema español de participación política.

Valencia: Universidad Politécnica de Valencia, 2005.

Montesquieu, Charles. Del espíritu de las leyes. Madrid: Tecnos, 2007.

Oliver Araujo, Joan. "El referéndum en el sistema constitucional español". Cuadernos de la Facultad de Derecho, núm. 15 (1986): 95-148.

Oliver Araujo, Joan. "El referéndum en el sistema constitucional español". Revista de Derecho Político, núm. 29, (1989): 115-182.

Parodi, Jean Luc. La politique. París: Hachette, 1972.

Rallo Lombarte, Artemi. Garantías electorales y Constitución. Madrid: Centro de Estudios Políticos y Constitucionales, 1997.

Real Academia de la Lengua Española. "Plebiscito" en Diccionario de la lengua española. https://dle.rae.es/?id=TOBzlgN (acceso mayo 18, 2018).

Real Academia de la Lengua Española. "Referéndum" en Diccionario de la lengua española. http://dle.rae.es/?id=VcEQ6Jm (acceso mayo 18, 2018).

Real Academia de la Lengua Española. "Tribuno" en Diccionario de la lengua española. http:// dle.rae.es/?id=acLJm5b (acceso mayo 18, 2018).

Rousseau, Jean Jacques. El contrato social. Barcelona: Atalaya, 1988.

Sáenz Royo, Eva. "La regulación y la práctica del referéndum en Suiza". Revista de Estudios Políticos, núm. 171 (2016): 71-104.

San Vicente Feduchi, Jorge. "Referéndum". Eunomía, núm. 14 (2018): 274-284.

Sánchez Ferro, Susana. "El referéndum de independencia escocés: ¿Evolución o revolución del derecho constitucional británico?". Revista Española de Derecho Constitucional, núm. 103 (enero-abril 2015): 111-156.

Santamaría Pastor, Juan Alfonso. "Comentario al artículo 92 de la Constitución Española de 1978" en Comentarios a la Constitución, coordinado por Fernando García Falla, 1448-1461. Madrid: Civitas, 2001.

Tierney, Stephen. Constitutional Referendums. The Theory and Practice of Republican Deliberation. Oxford: Oxford Constitutional Theory, 2012. 